\title{
English Medium Instruction in Universities: A Collaborative
}

\section{Experiment in Turkey}

\author{
Ernesto Macaro $^{1 *}$, Mustafa Akincioglu ${ }^{1} \&$ Julie Dearden $^{1}$ \\ ${ }^{1}$ Centre for Research and Development in English Medium Instruction, University of Oxford, Oxford, \\ UK \\ *Ernesto Macaro, E-mail: ernesto.macaro@education.ox.ac.uk
}

\begin{abstract}
We report on a study exploring the level of success of collaboration in lesson planning between English language specialists and content teachers in Turkish universities where academic subjects are being taught through the medium of English. Although some previous research exists on collaboration of this kind at the secondary education level, and there is some reference to it in Content and Language Integrated Learning in Europe, no research to date has explored the potential for collaboration between specialists at the tertiary level. Using pre- and post intervention interviews with nine "collaborating pairs" of teachers using a "collaborative planning tool" we additionally explored content teachers' beliefs about their students' language competence, their conceptualization of language as a medium for understanding content, and their knowledge and beliefs about the preparatory English programme. Our findings on the whole suggest that collaboration of this sort can be highly beneficial and we provide case studies of both successful and less successful aspects of the intervention.
\end{abstract}

\section{Keywords}

second language learning, teacher collaboration, English Medium Instruction, Higher Education

\section{Introduction}

English Medium Instruction (EMI) refers to the teaching of academic subjects through the medium of English in non-Anglophone countries. In Higher Education (HE) it is a phenomenon which is growing rapidly (Dafouz \& Guerrini, 2009; Doiz, Lasagabaster, \& Sierra, 2013) but in fact a recent 55 country survey (Dearden, 2014) found that it was not only in universities that the trend demonstrated a clear increase, but secondary education was also widely adopting EMI, possibly under top-down pressure from universities; typical examples are those of Hong Kong (Lo, Y. Y., \& Lo, E. S., 2014) and of Malaysia (Yassin et al., 2010). With special relevance to the current study, Kirkgöz (2005) reports that Turkish students' motivation for selecting English medium education is primarily instrumental (obtaining better paid jobs and being more broadly educated through EMI).

A number of drivers appear to be propelling the rapid expansion of EMI in HE, among which: public 
sector education trying to compete with private sector education (Dearden, 2014); the desire for universities to internationalize and thereby increase revenue from foreign students thus necessitating English as the language of instruction (O'Dowd, 2015); a perceived need for university managers to improve their institution's position in international university rankings (Rauhvargers, 2013; Lehikoinen, 2012); and a recognition that, in a globalized world, home students need higher levels of English language competence if they are to compete on the international market (Graddol, 2006).

However, whether EMI in HE improves students' English language competence more effectively than studying English as a subject (English as a Foreign Language; EFL) is yet to be demonstrated through research (Byun et al., 2011; Lei \& Hu, 2014). This is because EMI, unlike its European, largely secondary education, counterpart "Content and Language Integrated Learning" (Aguilar \& Munoz, 2014; Lasagabaster, 2011) does not have, either in its title or clearly articulated in its educational policy, an aim to "teach English"-merely that the subject content will be taught through English. Moreover, there is very little concern among policy makers and university managers (Byun et al., 2011) that students might be disadvantaged by not being able to understand the English being used by their teachers. In other words the speed and lack of preparation for EMI in HE not only ignores a need to demonstrate its effectiveness as a new pedagogical method for promoting English (as opposed to EFL), but also disregards the danger that students will not understand the content that is being presented to them.

Turkey has been increasing its EMI university offer (Kırkgöz, 2005; Coşkun, 2013). According to Coşkun (2013), of the 53 state universities in Turkey, 23 use EMI. Government universities that deliver courses through EMI have been perceived as being more prestigious than those that do not. In 1984 the first private university, Bilkent University, was established, claiming to be 100\% EMI. Since 2000 the number of private universities has rocketed and one of the key marketing points that they have openly promoted is that they deliver courses through English.

Kılıçkaya (2000) provides evidence, through questionnaire data, of some resistance to the introduction of EMI suggesting that Turkish EMI teachers would prefer to adopt Turkish as the instructional language. However, Turkish universities, on the surface, would appear to have addressed some of the language issues by introducing what is known as the "Preparatory Year" or "Preparatory Year Programme" (PYP) which is taught by English language teachers with varying degrees of teaching experience and consist of both native and non-native speakers of English. These PYPs are aimed ostensibly (as the title of the course suggests) at preparing students to study their academic subjects through English. It is also conceived as a bridge between secondary education and tertiary EMI education, in part because of the varying levels of English language competence that Turkish students have when they finish their secondary education. Since 2005 Anatolian High Schools have lost their special status (Ministry of Education, Turkey (Note 1)) which included having a 1 year PYP and now deliver core subjects (Maths and Science) through English. On the other hand currently no government high school delivers subjects through EMI. Only private High Schools can deliver subjects through the 
language/s of their own choice provided that they meet the criteria set by Ministry of Education. It is therefore of considerable interest to ascertain how well the PYP in universities is preparing students for EMI. A recent study involving 38 universities in Turkey (British, 2015) concluded that the PYP was inadequate and recommended reducing the number of EMI courses by raising the bar on the level of English needed by students in order to be admitted to those courses, a policy which some may consider anti-egalitarian because students with higher English proficiency may predominantly come from private High Schools.

One approach taken by researchers in order to investigate the skills levels that PYPs could provide, in order to ensure EMI effectiveness, has been to investigate the beliefs of teachers and students. Kirkgöz (2009) investigated teacher and student perceptions of the effectiveness of English language instruction in an EMI university in Turkey and found that over $90 \%$ of students did not consider it to be preparing them adequately to learn academic subjects through EMI. Inan, Yuksel and Gurkan (2012) collected data from teachers in EMI departments at two Turkish universities in order to investigate what they considered the linguistic skills needed for the first year of EMI as they transferred from their PYP programme. The receptive skills of reading and listening (to lectures) were by far the most cited. Speaking was not considered particularly important a skill for the PYP to develop perhaps reflecting the uni-directional nature of the teaching that was the norm in EMI lectures. Akyel and Özek (2010) used questionnaires and interviews, with both EMI teachers and students, to explore skills requirements in a single Turkish university and found that the teachers focused more on reading and listening as the important skills to be developed. However, both teachers and students felt the PYP neglected speaking skills which allowed students to operate successfully in their (undergraduate) EMI programmes. Coşkun (2013) collected teacher and student data from a single Turkish university and concluded that it was difficult to evaluate the PYP because it did not have clear objectives and even argued that it be scrapped and replaced, after a curriculum needs analysis, with a more appropriate and manageable programme.

Turkey is one of a handful of countries to have adopted the PYP model for the introduction of EMI. Another is Saudi Arabia which might serve as a comparison. Using an online survey, McMullen (2014) investigated whether gender and geographical location (of the university) affected Saudi students' perceptions of the value of the PYP. In general females demonstrated a greater keenness to take part in the PYP but there was also considerable variation among the universities investigated suggesting that the quality of the programme made the difference. Students in McMullen's study proposed that a good PYP course should substantially enhance students' productive skills (speaking and writing), something which the course did not seem to be achieving. Also in Saudi Arabia, Kabouha and Elyas (2015) examined the PYP curriculum to see the extent to which it aligned with the intended learning outcomes, assessment system and pedagogy. They found a remarkable disjuncture between what the PYP was trying to achieve and what in fact it did achieve in terms of student outcomes. Finally and perhaps most importantly for the current study, Aburizaizah (2015), on the premise that the PYP at King Abdulaziz 
University was not achieving its intended outcomes, investigated the feasibility of introducing a more CLIL-like programme involving both English teachers and EMI teachers. Surprisingly it was students who had reservations about this development towards greater integration of language into content.

One possible motivator towards a more CLIL-like approach to EMI teaching has been the introduction of "Flipped Classrooms" (Bishop \& Verleger, 2013). We find that a number of Turkish Universities, including some in the current study, have begun adopting this methodology in which the traditional classroom is "inverted". Flipped classrooms take a variety of forms but one approach is for the lecturer to pre-record on video his/her lecture so that students can study it in advance of the face-to-face lecture, garner some understanding of the topic, and identify questions that they want to ask. It is not the purpose of the current article to discuss the value of the flipped classroom.

However its introduction, in an EMI setting, does have implications, as our study data will show, for how a lecturer might go about planning lectures and thinking about language in order to ensure his/her students' comprehension of content.

A need for a rethink of the way that HE students are prepared for studying an academic subject is not exclusive to the EMI situation. In a recent comprehensive volume on English for Academic Purposes (EAP) mainly focusing on Anglophone universities, Wingate (2015) argues that: a) there is too much emphasis on academic writing skills to the detriment of other skills; b) the instructional focus is not sufficiently subject specific; and c) students are not sufficiently socialised into a community of practice which Wingate expresses as: "the ability to communicate competently in an academic discourse community" (p. 6). The PYP, we would argue, is a form of general EAP course in an EMI setting as opposed to an Anglophone university context and this raises questions explored in the current study.

Academic language is a broad term used in the EAP research and professional literature alike. A distinction that is often made is the difference between academic language and the "vernacular" (or everyday language), that people use both inside and outside classrooms. One of these distinctions is made by Cummins (1979) between BICS and CALP. However Wingate's (2014) work would suggest that English CALP needs further breaking down into subject specific terminology: for example, between "crankshaft" (in engineering) and more general academic vocabulary (with terms such as "specific" "a distinction made", "would suggest that", "additional considerations"-all academic language taken from the current paragraph). However, for the EMI students there are additional considerations: the polysemous nature of words in English; collocational obscurities and their distribution in clauses; and the lack of match of both of these with the students' L1. Consider for example the word "solution" and its various meanings in different subjects and the high probability that "solution" in the L1 has three different corresponding words in the L1. For example, in Turkish "solution of a maths problem" is "Problemin çözümü"; a "chemical solution" is "Kimyasal çözelti" and there is no direct corresponding collocation for "historical solution".

The language specific to subjects, and in relation to English as an L2, has received relatively little research attention in the HE context. A possible exception is a study by Evans and Morrison (2011) 
showing that Hong Kong first year university students report considerable difficulties in understanding technical vocabulary. On the other hand at the secondary school level, and particularly in science, research has built up a considerable body of evidence to demonstrate that to teach though an L2 requires teachers to think carefully about their explanations of science concepts (Marshall, Gilmour, \& Lewis, 1991; Othman \& Saat, 2009).

A better understanding of the difficulties faced by university students on EMI courses might come about, we hypothesise, if there were greater collaboration between the PYP tutor who (in principle) should be a language expert, and the EMI teacher as the subject expert. Davison (2006) explored the benefits of co-planning and co-teaching between English (ESL) and EMI teachers in Hong Kong, again however, at the school level not in HE. For the collaboration to be effective he argues for the need to establish: "a clear conceptualization of the task, the incorporation of explicit goals for ESL development into curriculum and assessment planning processes, the negotiation of a shared understanding of ESL and mainstream teachers' roles/responsibilities ... and the establishment of systematic mechanisms for monitoring, evaluation and feedback" (p. 456).

Lo (2014) suggests that there are various levels at which collaboration can take place. At a very basic level the English specialist can simply proof read the language used in teaching materials. Higher levels might involve careful co-planning and even co-teaching but she acknowledges that teachers perceive a strict division between the roles of the language teacher and the content teacher. Indeed some might feel threatened if their power and status relationships are undermined. Lo's (2014) study, set in an EMI secondary school in Hong Kong lasted 20 months, and involved English language teachers and content teachers in the design and teaching of four units in the Science and Humanities. Lo reports that teachers reached a better understanding of the needs of their students, changed their pedagogical foci and there was even some evidence that the students improved their language competence. Also at the school level (and in the European CLIL context) Pavon Vasquez et al. (2015) analyzed lesson plans in primary schools where content teachers and language specialists collaborated at a number of levels and found that teachers were aware of the potential of co-ordinated activity. However, realising this in actual collaborative designing of activities was less straightforward.

In summary, EMI in universities is increasing across the world and Turkey is no exception. Turkish universities attempt to prepare their students for learning their academic subjects through English but the effectiveness of PYP programmes has to date been called into question. A lack of clarity persists with the objectives of the PYP. There is a lack of specificity as to the way it is preparing students for EMI programmes and questions need to be asked as to whether there should be a more subject specific focus given the demands brought about by the complexity of academic concepts in certain disciplines.

As a result of this previous research we decided to investigate whether an intervention might bring about a change in the views and practices of EMI teachers in Turkey.

Our research questions were:

1) How does collaboration in planning evolve between a PYP teacher and an EMI teacher? 
2) What factors make collaboration successful or less successful?

\section{Methodology}

We carried out a larger project adopting a mixed-method research design. For reasons of space, here we report only on the part of the project in which we describe in qualitative terms the results of the "intervention" which was conceived as a series of collaborative lesson planning sessions involving a PYP teacher and an EMI teacher. The larger project also included students' perceptions of EMI.

To form the intervention group we invited eleven Turkish universities whose members had previously attended an EMI course at an Anglophone institution and had expressed an interest in taking part in a research project.

After considering the nature of the project, four of the eleven universities agreed to form the "collaborating pairs" of PYP and EMI teachers, which resulted in ten pairs initially with nine of those completing the intervention as planned (see Table 1). One selection criterion for our EMI teacher participants was that they were teaching their academic subjects to first year EMI students, the justification being that the majority of these students would have come directly from the PYP (a minority go straight into an EMI programme based on English language ability) and therefore the data regarding linguistic preparation would include a focus on the effectiveness of the PYP. The formulation of the collaborating pairs was made on a voluntary basis usually resulting from the two teachers being previously acquainted at some level. High level ethical procedures were adhered to including participant consent forms.

Table 1. List of Participant PYP Teachers and EMI Teachers

\begin{tabular}{|c|c|c|c|c|c|}
\hline \multirow{2}{*}{ University } & \multirow{2}{*}{\multicolumn{2}{|c|}{ Pairs }} & \multicolumn{2}{|c|}{ Teaching Experience } & \multirow[t]{2}{*}{ EMI subject } \\
\hline & & & Total Years & Through EMI & \\
\hline \multirow{4}{*}{ University 1} & \multirow{2}{*}{1} & (PYP_1) & 23 & 23 & \\
\hline & & (EMI_1) & 19 & 19 & Chemistry \\
\hline & \multirow{2}{*}{2} & (PYP_2) & 24 & 24 & \\
\hline & & (EMI_2) & 4 & 4 & Chemistry \\
\hline \multirow{8}{*}{ University 2} & \multirow{2}{*}{1} & (PYP_1) & 25 & 25 & \\
\hline & & (EMI_1) & 3 Months & 3 Months & Economics \\
\hline & \multirow{3}{*}{2} & (PYP_2) & 4 & 4 & \\
\hline & & (EMI_2) & 3 Months & 3 Months & Computer \\
\hline & & & & & Programming \\
\hline & \multirow{2}{*}{3} & (PYP_3) & 3 & 3 & \\
\hline & & (EMI_3) & 3 Months & 3 Months & Engineering \\
\hline & 4 & (PYP_4) & 4 & 4 & \\
\hline
\end{tabular}




\begin{tabular}{|c|c|c|c|c|c|}
\hline & & (EMI_4) & 27 & 27 & Engineering \\
\hline \multirow{4}{*}{ University 3} & \multirow{2}{*}{1} & (PYP_1) & 17 & 17 & \\
\hline & & (EMI_1) & 25 & 25 & Mathematics \\
\hline & \multirow{2}{*}{2} & (PYP_1) & 17 & 17 & \\
\hline & & (EMI_2) & 16 & 16 & Physics \\
\hline \multirow{2}{*}{ University 4} & \multirow{2}{*}{1} & (PYP_1) & 4 & 4 & \\
\hline & & (EMI_1) & 8 & 8 & Mathematics \\
\hline
\end{tabular}

\subsection{Research Instruments}

In order to provide a framework through which the pairs could develop their discussion on lesson planning (and to contribute to answering our second research question), we devised a Collaborative Planning Tool (CPT) that included prompts and questions to help the collaborating pairs reflect on the language content of the lecture (see Appendix). The main focus was on the lexical content of the lectures.

During the intervention the PYP teacher and the EMI teacher pair were expected to audio record each collaborative planning session, and to keep a record of relevant materials; that is, communication between herself/himself and the EMI teacher on lesson planning, hand written notes on planning and so on. Again space does not allow us to report on these data. We instead restrict our reporting to the EMI teacher interviews. One of the researchers conducted nine pre-intervention and nine post-intervention semi-structured interviews with nine participant EMI teachers. Pre-intervention interviews focused on the academic background of the EMI teachers, their perceptions of their students and their outlook on teaching academic subjects through EMI. Post-intervention interviews, focused on their perceptions of collaborative planning, the use of the CPT, and any changes in their perceptions of teaching through EMI. These interviews were audio recorded (pre-intervention interviews: 238.12 minutes, post-intervention interviews: 152.31 minutes, a total 390.43 minutes of audio recording). The researcher transcribed 18 interviews, $44 \%$ of which were also transcribed by another researcher for the purpose of reliability of transcription and coding.

\subsection{Procedure}

Prior to the commencement of the study, one of the researchers visited the participating teachers in order to explain what was expected from them, providing clarification on the purpose and use of the CPT, and answering any further questions pertaining to the study.

The expected sequence for a collaborative planning session was:

1) Collaborating pair agree on a working calendar;

2) EMI teacher sends the materials to be used in the lecture to the PYP teacher;

3) PYP teacher considers some of the key lexical level linguistic challenges and during the collaborative planning sessions PYP and EMI teacher discuss how to meet these linguistic challenges;

4) EMI teacher amends (if need be) the language content of the lecture;

Published by SCHOLINK INC. 
5) EMI teacher delivers the planned lecture;

6) In the subsequent planning session EMI teacher provides PYP teacher with the feedback on the delivered lecture.

\section{Findings}

Following procedures (Miles \& Huberman, 1994) recommended for extracting categories from raw data, we read multiple times the transcripts of pre- and post-intervention interviews with a focus on the EMI teachers' perceptions and beliefs about teaching through the medium of English and extracted categories which then served for coding the entire corpus of interviews.

Pre-intervention extracted categories:

1) EMI teachers' own English language proficiency; time spent in an Anglophone country;

2) Pedagogic training they had received in relation to EMI;

3) Students' English language level and more general academic skills;

4) Their thoughts on the PYP;

5) Their conceptualisation of planning curriculum/syllabus and lessons;

6) Material preparation for lectures and their linguistic awareness in relation to these;

7) Self-monitoring and use of feedback in lesson planning and delivery.

Post-interventions extracted categories:

1) The use and benefits of the CPT;

2) Collaboration with a PYP teacher in terms of;

3) Effective planning with better awareness of language issues;

4) Better understanding of the work done in PYP;

5) Gaining a self awareness of their language competence;

6) Continuation of collaborative planning with a PYP teacher in the future.

Our findings are presented in two sections: (1) pre- and post-intervention EMI teacher perception and beliefs, (2) three case studies. Selection of the case studies was made using the notion of maximum variation (Teddlie \& Tashakkori, 2008) in order comprehend the range of possible outcomes of the intervention within the word length constraints of this paper.

\subsection{Pre-Intervention Interviews}

EMI teachers made little reference to their own English language proficiency, whether general proficiency or discipline-specific proficiency. Rather they appeared to prefer to comment on the recruitment requirements they had needed to meet in order for them to secure their current posts. They reported that in order to meet the language requirement for recruitment they either had had to prove that they had graduated from full-EMI universities (in Turkey or abroad) or they had sat a language proficiency test (in-house prepared or standard tests, i.e., IELTS, TOFEL, etc.) to demonstrate that they met the minimum required level of English. Interestingly, although all of them had spent varying periods of time in Anglophone countries, they rarely referred to these experiences in relation to their 
current language abilities and those needed to teach through EMI.

None of the teachers had received any professional development in pedagogy prior to starting their teaching of their subject nor at any stage during their teaching career. This was the case for pedagogic development in general, and for any kind of training needed specifically to start, or switch to, EMI.

The majority of the respondents commented extensively on both the academic skills and English language skills of their students. In terms of academic skills, most of the participant EMI teachers agreed that the students are by and large ready for their academic subject studies at undergraduate level. However, one of the participant EMI teachers commented that, according to his colleagues and his observations, the academic readiness of students had decreased noticeably during the last decade.

In terms of the English language skills the respondents without exception believed that most students' language skills were not at a satisfactory level to start their academic studies through English. One participant's observation is typical:

"[T]his is my biggest concern, not all of them (students) but some of them, they cannot even ask proper questions".

This observation is particularly interesting because it appears to suggest that for these teachers at least, oral participation in class does or should take place and that they consider it to be necessary for understanding content.

Given that most students came to these EMI teachers' lectures from the PYP, it is clear that the latter did not in general consider that the programme was doing the job it was intended to do. Delving deeper therefore into this issue we found that virtually all the EMI teachers considered that the PYP curriculum and assessment system was inadequate. Although students completed the PYP and passed the language tests, most students were not ready to study through English. The area of deficiency most frequently cited was a lack of discipline-specific language in English. As one of the EMI teachers observed:

"I think they (PYP teachers) prepare (students) just for regular English lectures not for scientific lectures not for physics not for other scientific lectures".

The theme of the differences between general English, general academic English and discipline-specific English surfaced again and again. In terms of learners' subject specific language readiness for their academic studies, it was also frequently pointed out that students who have better levels of English and with subject specific terminology, come from specialised government or private high schools where they have already studied some of the core subjects through English.

In terms of planning for individual lectures all interview respondents commented that, although they had a rough idea in their mind as to what to teach and in what order to teach, they did not prepare individual lecture plans in pre-determined formats. As one of the participants admitted:

"I don't write this (lesson plan) down (because) I have all this in my mind, automatic".

This aspect of planning is particularly interesting. Although all of the respondents informed us that they prepare (individually and/or together with their colleagues within their subject departments) a general curriculum for every course to be delivered, none of them claimed to write down a detailed 
lecture/lesson plan. Certainly there was no mention in the pre-intervention interviews of any systematic thinking about the English that they were going to use (whether orally or in written form for slides or lecture notes) in order to try to match the students' English language levels. One of the respondents did comment on working collaboratively occasionally within the subject departments with the colleagues on planning lectures but this happened rarely because "we don't come together [that much] with my colleagues ... they are too busy". This remark might be taken as implying that if more time were available, lecture/lesson planning in greater detail and with a focus on language might be beneficial.

In response to a question about material preparation for individual lectures, the respondents commonly remarked that they mostly made use of resources written in English, and usually written for an international market or for native speakers of English (rather than for Turkish students). The general feeling was that their decision to use English materials not only resulted from the fact that they delivered courses through English (thus ensuring written sources matched the classroom delivery language) but also the fact that materials written in English offer a much wider range of choices. In line with this view and in response to a question asking whether they thought their students might learn better if they made use of sources written in Turkish, one of the EMI teachers commented that he did not think that the students would learn the subjects better if they studied through Turkish. On the contrary, studying through EMI was more effective as he believed that sources written in English not only have a more systematic approach to the academic topics but also include a wider range of authors enabling students to acquire a broader understanding. In the case of science we interpreted this greater systematicity as a more "Western approach to science". There is a need for a further exploration of this distinction and its origins.

Formal reflection on lectures/lessons taught (in the sense of a written record) appeared to happen rarely according to the pre-intervention data. On the other hand most respondents commented that they informally noticed when students were not able respond to questions. If this was the case, then in the following lesson, they said they made sure they provided students with more explanations and examples in order to address the points that had not been understood. However, in these comments there was no separation of language and content. In other words, if the students showed lack of understanding by not answering questions, there seemed to be no attempt to identify whether this was a language problem or a conceptual/content problem.

One teacher of engineering did remark that she used the attendance sheet both for keeping a formal record of the attendance (although it is not compulsory) and for taking notes on individual students. She remarked that she had found these notes useful in terms of following her students individually and noticing their learning needs, and also in terms of reflecting on the lesson as a whole.

\subsection{Post-Interventions Interviews}

The post-intervention interviews, began with an open question about the teachers' experience with using the collaborative planning tool during the planning sessions with their PYP counterpart. Firstly we found that different pairs had interpreted the function and potential of the tool in different ways and 
had followed the suggested procedures to varying degrees. Some of them found the CPT useful in terms of giving a structure to their collaborative planning with their PYP counterparts but most of them commented that after the first couple of planning sessions they followed it less closely as they already had become familiar with the order of the prompts the CPT provided for them. Thus rather than using it as a rigid artefact they preferred using it as list of structured prompts and questions which framed their discussions. We should also mention that none of the collaborative planning pairs used the CPT in a way that allowed for the collection of texts and other materials that they were going to use. We had hoped that they would insert some of the text from the resources they used into the boxes provided in the CPT Word template and in this way collect a body of subject-specific information which could have been documented in a research paper. On the other hand given that we were able to record the collaborative sessions we intend to publish some of this data in future.

When asked if they had found planning collaboratively with a PYP peer effective in terms of gaining a better awareness of language related problems that their students might have, the majority of EMI teachers commented positively. Some responses related to word-level problems. Those EMI teachers who had addressed, with the help of CPT, word level language issues commented that they gained a better understanding of noticing and addressing lexical issues during the collaborative planning sessions. Perhaps more interestingly, some of the EMI teachers remarked that, their beliefs about the interplay between language and content had evolved. One of the participant EMI teachers offered the following:

"We have two languages in physics; one is mathematics, the other one is English. Before this project, I thought mathematics as a language was more important but now I feel that the first medium should be English and this may be a little more important than mathematics for teaching undergraduate level, English must be more important in teaching physics in undergraduate level”.

From this quote we can see how the relationship between language and content is extremely complex and the teacher seems to be struggling to articulate it not because she/he does not have sufficient English to do so but because she/he has not yet arrived at a definitive understanding of that relationship. The complexity seems to lie in whether mathematics (as it is used in the study of physics) is sufficient as a linguistic code in itself or whether it has to have an additional referent-general academic language and the vernacular. If the latter is the case then general and academic English both need to be considered much more carefully by the EMI teacher and additionally related to the experience level of the student (undergraduate or postgraduate). If our interpretation is correct then this is the opposite of saying (as was raised in the pre-intervention interviews) that the PYP programme should be teaching them "technical language". Moreover, it may be inferred from the above quote that there are levels of "gaining awareness on language related issues" for EMI teachers. Developing a more effective approach to lesson planning, involving reflection on language, may need several iterations of collaborative planning and, possibly, some form of action research.

A growing awareness of language issues was also reflected in statements about progression in English 
proficiency across the educational phases, in that not each phase necessarily built on the previous one. In support of this interpretation an EMI teacher observed:

"[...] for me it (planning collaboratively) was effective because I was enlightened about the language level of the students. Before I saw this is a continuation of education ... you go to primary school (then) secondary school high school and (then) university. But when I had a chance to think about PYP and English education of the students, I started to see is that it (language education) is not part of a continuation".

The post-intervention interviews also collected data on whether participants had now gained a better understanding of what the PYP offered in terms of language preparation. In this we found another contradiction. On the one hand some teachers had come to a realisation of their own role in considering language to be an important factor in ensuring content understanding. On the other hand, most once again commented that they did not think that the PYP prepared students well enough, again citing the lack of subject specific academic vocabulary. One participant went so far as to say that, to her knowledge, the students were taught English at PYP through EFL-type communicative topics which did not help them to gain enough subject specific academic language to cope with the language demands of the subject departments.

The interviews closed by asking whether the EMI teachers would like to continue to plan collaboratively with a PYP teacher in the future. All of the teachers were positive about the prospect of continuing collaborative planning although with very differing levels of expressed enthusiasm. Moreover, they had different views on how this collaboration might continue. Some suggested that the framework for collaborative panning (the CPT) could be improved in a way that would address the particular needs of different subject departments. Some teachers suggested that this type of collaboration might happen just once at the beginning of new courses. Others hinted at a general applied linguistics perspective they could gain from PYP teachers. Perhaps one of the most interesting positive comments came from one EMI teacher who was also the head of the subject department. He ardently supported the idea of looking for more structured and sustainable relations between his department and the PYP department. He said:

"I'd love to do that (continue to plan collaboratively). I got criticism (meaning feedback) when I prepare the videos and the other materials for my lectures. My presentations became better and better, this project helped me. I asked the principal and the university admin to continue to this collaboration, in the same way I experienced, being in communication with PYP. We want to continue this because this is (collaboration between the Engineering Department and PYP) is good for our students and also for our instructors". 


\section{EMI Teacher Case Studies}

\subsection{EMI Teacher Adnan}

Our first case study was of Adnan who reported having four years experience of teaching Physics via EMI. As with all other teachers in this study he had not undergone any preliminary teacher education or training programme. He had taken a state language test and reported having achieved an excellent score so we can assume that he was highly proficient in English as the transcript of his interviews in fact attests.

In the pre-intervention interview, when talking about his students, Adnan rated most as average, 5\% as very good and $10 \%$ as poor, the last not having even "basic mathematical skills". Comments and judgements related almost entirely to knowledge of physics rather than any reflection on his students' language ability. In fact Adnan appeared to find it difficult to differentiate between whether students were having problems with Physics or the English language and whether or not the students were familiar with the genre of Physics.

Before the intervention, Adnan appeared to believe that language was not an issue in mathematical problems "They mostly need to calculate, the language doesn 't come into play", and some problems "don't require any language skills such as multiplying two entities".

At this stage Adnan was aware that language became an issue when it came to the "more Physics types of questions" which had a narrative "such as an object is thrown at a certain angle at a certain speed and it bounces back from a certain object" and it was this sort of problem that students could not easily deal with, possibly because of language.

Adnan welcomed the arrival of international students in the class. Their presence meant Turkish students were forced to listen in English rather than switch off during the lecture and rely on a short explanation in Turkish in the last five minutes of the lecture.

In the pre-intervention interview the issue of "shyness" arose. The inability of the students to interact in class, to ask questions or answer comprehension check questions was interpreted by Adnan as students being "shy" or due to "some language barrier or some other cultural problem" rather than a specific English language deficiency. Thus he did not consider low levels of English proficiency as a possible reason for student silence even though "when I tell them they can ask in Turkish, they start asking questions".

Although he expressed dissatisfaction at the way the PYP year prepared students for studying Physics in English, he still thought this might be because students were "too shy to speak".

By the time of the post-intervention interview Adnan's understanding of the importance of language in Maths had changed noticeably:

"We take Maths as a language, we give formulas, we say $F$ is equal to Mxa. Technically speaking if the students are perfect in Maths they don't need to know the language you are using, they will perfectly understand what you mean. But in reality we need to explain these formulas, we need to support mathematics with language". 
Before the intervention Adnan had some inkling that general English words have a different meaning when used in a subject-specific context. For example when teaching "normal force" he first asked what the meaning of "normal" was and then merely said that in Physics it meant "perpendicular". In the post-intervention interview, he seemed to have a more conscious understanding of the importance of systematically explaining the technical meaning of a word which might also exist in general everyday language. In the pre-intervention interview Adnan had cited the example of capacitors which consist of two parallel "plates".

“Whenever I say 'plates' I expected my students to understand flat geometrical structures".

During the intervention the PYP teacher made him realise that the student learned "plate" as an "eating from thing" and this was a revelation: "when she made me realise that, it was enlightening!"

Before the intervention Adnan assumed that because the students had spent a year in PYP they would have a certain level of English but collaborative planning helped him to realise that "I still have to stress and define each of these words for them [students], even the simple ones". He elaborated on this increased linguistic awareness:

"Before, I defined the capacitor as two parallel metallic surfaces and go on teaching, now it's different. I need to define better even for native and non-native speakers and go a little deeper to make sure they understand".

Like other teachers in the study, Adnan raised the problem that students had in understanding exam questions in English:

"When I'm grading in the exam and I ask really simple questions and when I see they cannot answer I feel sad".

Some students did not succeed in exams simply because they did not understand the vocabulary in the question. Like other teachers in the study Adnan mentioned that he might translate key words in the exam questions but was uncertain if this was the "right" thing to do.

In summary, the intervention, via the collaborative-planning sessions seemed to help Adnan go through a personal transition in his conceptualization of the challenges that students faced: from a focus on subject ability and shyness or reluctance to participate through English (a student-centred problem), to a focus on the complexity of language and the effort needed to put across meaning (more of a teacher-centred problem).

\subsection{EMI Teacher Burcu}

Our second case study is of Burcu. As a recently appointed assistant professor in the Department of Industrial Engineering, Burcu had various experiences of teaching and learning through a foreign language. As a student she had taught courses in German to Turkish students, tutored problem-solving sessions in English and led an advanced research course in English with international students in Belgium. This multi-lingual, multi-cultural background is perhaps more typical of younger EMI faculty who begin by studying, and then teaching, abroad and perhaps therefore recognise the importance of English for academics. As Burcu explained: 
"As an academic it is very important that I am able to speak in English and I am able to explain things in English because I have to publish in English, be able to read in English this is natural".

An interesting aspect of teaching and learning in EMI in Burcu's university was that teachers used the "flipped" classrooms system. Lectures were pre-recorded by teachers and watched online by students before the class, so that the class time was kept for questions and discussion. This teaching approach presents an alternative perspective on the EMI context. Firstly, it is very different from the monologic lectures Burcu had experienced as a student:

"I was seeing the professors coming into the classroom turning their back to us and writing on the board during the lecture".

Secondly it became evident from the pre-intervention interview that Burcu involved herself in a great deal of preparation when making each video-lecture and gave consideration to exactly what she would say, the connection between slides and to the structure of the lecture: "for every slide I also write down what I'd like to say for that slide". Each lecture was written, rehearsed, filmed and edited. It was also shorter than a face-to-face lecture, approximately 13 minutes in her case. Perhaps then it was the nature of the flipped classroom itself that "forced" her to prepare in greater detail than most of the other participants in the sample.

Thirdly, in the flipped classroom system students are expected to discuss and ask questions in the classroom. In this case, even though students passed the university's proficiency test and a couple of students could speak English fluently, language problems did manifest themselves. As Burcu explained: "most of them don't have a sufficient level of English for this course" and students preferred to speak their home language in group activities. Burcu was concerned that the students could not express themselves in English and therefore could not ask questions and was frustrated when students asked the question in Turkish.

Fourthly, because of the nature of the programme she did not have a course book "so the only source they have is the written lecture notes that I prepare"-clearly requiring her to think even more deeply about her use of English. This led her to develop quite a high level of language awareness in reaction to students' lack of understanding:

"I used a simple word "investment". I didn't realise that some students didn't know the meaning of investment but they didn't ask me. What frustrates me isn't the fact that they don't know some vocabulary but they don't tell me that they don't know that word. I was trying to teach an important concept which is about investment and twenty minutes later they asked me what investment means?"

By the time of the post-intervention interview, there was evidence that Burcu had built on the foundations of her initial language awareness as a result of having had what appeared to be a very valuable association with her PYP colleague. For example the use of limited code-switching now proved useful and valuable for comprehension checking:

"I realised, in the beginning of the semester they were asking their question in Turkish although I was speaking in English. Starting from the middle of the semester they started asking their questions in 
English. They told me they wouldn't understand the lecture if it had been in Turkish! Even the students with low level of English started asking their questions in English, which was really surprising".

Moreover, after the collaborative planning sessions with the PYP teacher, Burcu started to think about "how I could explain these sentences, words, phrases better ... to paraphrase better, to give better examples". The PYP teacher supported her in this when preparing the video-lectures. Burcu illustrated this by an example, that of the "TSP, the Travelling Salesman Problem", which is apparently a famous problem in Industrial Engineering and involves the processing word "sequencing" as in "sequencing paint products for a production facility”. The PYP teacher offered linguistic support:

"He sent me an email saying that the students wouldn't understand the [concept of] sequencing ... sequencing for a production facility. So therefore, thanks to him, I put [in] some notes. Normally I would say what I mean by sequencing is putting the products into a successive order. Here they may not understand the word 'successive'so I used 'in an order ... one follows another'”.

By testing out vocabulary on the PYP teacher, a two way process of learning began to occur. Burcu became aware that technical content words, with which she was very familiar, posed a problem to students; conversely the PYP teacher obtained greater insights into technical language used in the subject:

"I used the word 'myopy'. He [the PYP teacher] was surprised because he never heard of this word ... A lot of word expression vocabularies are really familiar to me but in the end I understood that it's not obvious to the students".

In summary, at the beginning of the study Burcu had built an initial awareness of the issues involved in teaching through EMI, partly from having studied and taught abroad, partly from the exigencies imposed by the flipped classroom system. She now appeared to be understanding the linguistic challenges even more deeply. Also, importantly, her role as a teacher of an academic subject through English had clearly evolved into one where an integration of language into the learning process was an undeniable factor leading to successful learning. As she expressed succinctly: "we are responsible for many things I realised" and "teaching is not only about preparing the course content and going into the classroom".

Although the pre- and post-intervention interviews concentrated on the outcomes for the EMI teacher, it became clear in both Adnan and Burcu case studies that the PYP teachers also learnt from collaboration and indeed that this might be where such collaboration can make an additional significant impact.

\subsection{EMI Teacher Zeynep}

Our third case study is of Zeynep, an experienced teacher in a Department of Chemical Engineering who had been teaching through EMI for twenty-three years. The department had a long history of teaching in English starting in 1986 and had taught wholly through EMI since 1994.

In a similar way to the other teachers in this study, Zeynep had not received any initial teacher education. As she had studied at an EMI university herself she had not been expected to show further 
proof of English proficiency. When asked about her students, Zeynep considered them to have a good academic level in their subject, having been pre-selected by passing an exam before coming to university. She was not so sure about their level of proficiency in English as in each cohort, the level of her students' English varied quite widely depending on their family background, whether or not they had travelled abroad and if they came from an Anatolian High School.

Unlike the teachers in the other case studies, Zeynep was disappointed with the outcome of this project: "I thought in this project we could see many changes in our lessons but they didn't change too much in our lessons".

Zeynep worked with Gamze, a PYP teacher, but the pair did not find it easy to collaborate. It was emphasised that this was not a personal issue: "we like each other so much ... we are friends but on the subject of this ... was nothing”. It is therefore interesting to investigate the issues thrown up by this pair's difficult collaboration to shed light on areas needing greater consideration in the future. It was clear that both the EMI lecturer and the PYP teacher found the process itself alien. Zeynep had thought that it would "be so easy ... to work with the foreign language department ... but it was not so easy ... they do not have any idea about our lesson ...", whilst Gamze (according to Zeynep) found this particular subject and classroom setting not conducive to collaborative planning.

Interestingly the concept of collaboration per se was not alien to Zeynep. When talking about preparing the EMI courses she said that there were at least two EMI teachers teaching each course (100 students were divided into groups of 25 students per class). The teachers planned the course and selected materials, books, together: "naturally we always choose books in English". Like many other EMI lecturers, Zeynep used materials which "are written for English speakers ... that means good books ... good English and good pictures with pictures with suitable content". There was an inherent belief that English books were good books and no mention of these materials having been adapted to the Turkish context.

Zeynep believed that the PYP teachers were doing their best, but that the English that they taught was English as a Foreign Language and this was not the same as the more scientific English used in her Department. She knew this from both teaching and from her own experience as a PYP student twenty-five years previously:

"I also learnt English in the Preparatory Year. They taught us English with poems and songs. But when we came to our lecture room everything was different. I was in shock".

Her concerns for the PYP year were not only that the English being taught was not appropriate to her subject, but also that her students, who studied 100\% through EMI at university had the same PYP lessons and the same final PYP exams as students who went on to study only $30 \%$ of their degree through EMI. It was felt that the 100\% EMI students should be educated in a more specific English for their studies in Chemical Engineering and that the PYP exams should be adapted to the needs of a department teaching 100\% through EMI. She conceded that the problem of low levels of proficiency in English should not be blamed entirely on the PYP year, that High Schools should play their part.

Published by SCHOLINK INC. 
Zeynep's frustration that Gamze did not understand the subject or read tomes of Chemical Engineering in English was tangible in the post-intervention interview. Gamze had been encouraged to come to the Chemical Engineering Department to observe Zeynep's classes as it was felt that "[PYP] do not have enough information, enough knowledge about this department”. Zeynep also felt that Gamze did not really know what was expected of her from a linguistics point of view or perhaps did not understand the linguistic implications of lecturing through EMI:

"She didn't understand the lesson and she didn't know what to change in my lecture. The PYP teacher and diary always stayed at the same point, she couldn't make any suggestions ... she doesn't know the subject so she doesn't have anything to explain in the subject. This is the point. She doesn't have any idea about the real subject".

The "real" subject here for Zeynep is clearly Chemical Engineering, not English. There was no sense that an EMI teacher might need to take responsibility for students' comprehension in English. In any case at one point Zeynep declared that in her class: "first of all we don't have any language problems".

Yet in lectures Zeynep tried various techniques, attaching importance to using posters and visuals and to using her voice effectively as otherwise "they don't listen to you and play with their phones". Zeynep gave her students explanations, solutions, quizzes but "when I ask about the questions, they say they didn't understand because of the language". She integrated 15 minutes into her classes for students to ask questions but "if they don't ask, how can I know they didn't understand?"

This led to non-comprehension on the part of the students:

"I feel so happy every time I finish the lesson because I think they understood everything. But in the next lesson when I find out that they didn't understand that makes me nervous".

It seems that there was an expectation on Zeynep's part that a collaborative planning process involved the PYP teacher as a corrector of slides before the class. Zeynep sent her slides to Gamze before the planning session but this pair did not use the tool to work together, preferring to send each other emails. Zeynep was constantly disappointed that Gamze did not read more of her materials and "I think she didn't have enough time to do all the reading. And in the end she suggested one word in one sentence. That was a break point. I waited for more things to be changed, explanations for example".

It seems therefore that Zeynep was in a state of self-contradiction. On the one hand she did not believe there were language problems in her class: "first of all we don't have any language problems. ... The 'real' subject is Chemical Engineering, not English". On the other hand she observed that "they don't listen to you and play with their phones". She attempted to assess content understanding but "when I ask about the questions, they say they didn't understand because of the language". 


\section{Discussion}

This study explored how collaboration between English language teachers and EMI teachers from very different backgrounds might have the potential to bring about change in content delivery in EMI Higher Education contexts. The country in focus was Turkey, partly because of the interesting situation in that country where a preparatory year of English language teaching is intended to facilitate transition from largely Turkish-medium secondary education to English-medium tertiary education. In doing so we sought to investigate the changes in beliefs and reported practices of the EMI teachers after the introduction of collaborative planning and evaluation sessions during which an artefact, the CPT, was meant to be used in order to ensure that a number of important language issues, previously identified in the literature, could be addressed by the collaborating pair.

It is clear from the data collected pre- and post-intervention that the project had varying levels of success and perhaps this variation is best exemplified by the three case studies reported above. Interestingly, it seems that it was those pairs that used the CPT (even if only to some extent) for the purpose for which it was intended who had the most positive experiences and moved forward with their thinking.

Where change in thinking did occur this appeared to be mostly in the realisation of the intertwined nature of content and language. In that regard EMI programmes may need to reflect much more on the lessons learnt in the CLIL context in terms of what is meant by integrating content and language. Most of our participating EMI teachers considered themselves prior to the intervention to be content teachers only. After the intervention a shift had begun to occur. However, it would be inaccurate to say that they were now seeing themselves as language teachers-in the sense of aiming to further the language proficiency of the students. Rather they were seeing their role as ensuring that content comprehension was taking place, and if this needed further reflection on the English language, then they were prepared to contribute further time and effort into allowing that to happen. We would argue that this is not the same thing as considering themselves as teachers capable of integrating both content and language. They were not on the first step of a slow process of becoming CLIL or "Immersion" teachers (see for example Cammarata \& Tedick, 2012). In any case, even as they took on more responsibility for ensuring comprehension through more subtle use of language, their development was clearly an iterative process requiring more than a single and relatively brief intervention.

An interesting finding was that prior to the collaboration most EMI teachers focused on the students' English skills, not their own. Although our interview transcripts show that most teachers had high levels of English proficiency (we would estimate that all were at B2 level or above), nevertheless, there was rarely a reflection by them on their level of English needed in order to overcome students' comprehension problems. The language needed for explanation of difficult concepts to students with low English proficiency perhaps requires EMI teachers to have a broader repertoire of language genres and a consequent broader and deeper lexical store. As some of the participant EMI teachers realised by the end of the intervention, a considerable amount of the lecture time needs to have a focus on dealing 
with the language which revolves around the subject specific terminology. This issue has been well documented in immersion contexts (e.g., Probyn, 2001) but less in EMI contexts.

It was clear from the interviews that EMI teachers only had a superficial understanding of what the PYP curriculum consisted of. Yet they seemed to be fairly united in the belief that it was not delivering the level of English which allowed their students to thrive in EMI classes. Most mentioned the lack of focus in PYP on subject specific language and this echoes the call in EAP contexts for more subject specific English language input (Wingate, 2015; Murray, 2013; British, 2015) in either preparing students in advance of EMI or supporting them during EMI courses. In other words there would appear to be a real need for a two-way process of learning: EMI teachers need to become more proficient in identifying and addressing students' language problems in their classes instead of merely expecting them "to be ready for EMI" when they arrive; PYP teachers need to become more familiar and attuned with subject disciplines in order to be able to fully support students embarking on EMI courses.

The above aspiration is probably not as easy as it sounds and in any case raises the question of our expectations of PYP teachers, their linguistic knowledge, understanding of what EMI is, and consequently for the selection of PYP teachers and their training for this kind of collaboration in future. What should the role of the PYP teacher be in an EMI context? Should it be one of preparing students generically for their EMI course regardless of the subject they are studying? Or should they (perhaps in addition) be steering students towards socialization in a specific community of practice and the English terminology that is the currency in that community of practice? If the latter is the case then how will a PYP teacher know what the language that the students will be facing in the future unless they have themselves been taught that particular subject at some level? Moreover, would HE institution managers acknowledge the problem and provide resources for an on-going dialogue between the PYP teacher and the EMI tutor to occur and consequently for professional development?

In a sense this two-way process, we would argue, reflects a need for another process to occur at a higher level of abstraction as EMI continues to gain ground globally, and perhaps gradually replace EFL courses in HE - a situation not beyond the realms of possibility. That is, that the separate disciplines of Second Language Acquisition/Applied Linguistics on the one hand and "Subject Education" on the other hand need to come much closer together to create a positive synergy. By Subject Education, we mean all the pedagogical knowledge and understanding that we currently have about how learners best learn academic subjects in general and through interaction in particular (Mercer \& Littleton, 2007; Mercer, 2010).

It is no coincidence that much of the latter literature highlights the importance of quality interaction between teacher and students. At a theoretical level therefore a merging of educational research and applied linguistic research and expertise is not impossible. Teaching through the L2 requires teachers to consider how to engage their students cognitively. The negative effect that using English as an L2 may have on the quality of science classroom interaction has been demonstrated in other school-level research. For example, Lo and Macaro (2012) found that when Hong Kong teachers switched from 
Chinese medium instruction to EMI the interaction became much more teacher centred and "transmissive" (imparting knowledge through a lecture style) in nature. In our study among the more successful collaborations we detected the germination of a belief that a different pedagogical approach in $\mathrm{HE}$ is needed as a result of a switch to EMI, one which was in part reflected by the flipped classroom approach to lecturing. EMI may well need to be more interactive, supportive, and carefully scaffolded (Llinares et al., 2012) in order to facilitate understanding of complex concepts. To this end it would be useful for future EMI research to investigate whether "flipped classrooms" in fact do lead to more carefully structured and scaffolded interaction.

A number of limitations can be identified in the study reported here. It would have been informative to separately interview the PYP teachers both before and after the intervention. However, resources did not allow this; instead we have relied on what the EMI teacher sometimes said about the PYP teacher. We do have the transcripts of the planning sessions which may provide insights into the gradually developing thinking of the PYP teachers and we hope to report these elsewhere.

It would also have been very useful to video and analyse the lectures of the EMI teachers which resulted from the collaborative planning sessions but we detected some resistance to this early on and rather than jeopardise the whole project decided not to insist.

Lastly, we did not have sufficient numbers of participating pairs to ask the question: do the different subject disciplines throw up different linguistic problems for students and for potential collaboration between PYP and EMI teachers. This would certainly be an interesting question for further research to try to answer.

\section{Conclusions}

Our first attempt at an intervention into EMI teachers' thinking and planning for their lectures and lessons, through collaboration, has yielded some very interesting data and the project can be said to have been in a number of respects successful. Although the Collaborative Planning Tool may need to be modified, we believe that in principle something like it is needed to allow a focus on language in any future collaborations between the different disciplines of EFL and content subjects.

Because of internationalization, world rankings, and student mobility, we are aware that it is highly unlikely that the EMI phenomenon will be halted. It is because we feel that the phenomenon has a number of significant issues attached to it that we believe it should be every educator's responsibility to try to ensure the best possible outcomes for the current and future generations of students.

\section{Acknowledgements}

The authors are very grateful for the support provided by Oxford University Press (Turkey) in carrying out this research. 


\section{References}

Aburizaizah, S. (2015). Introducing content and language-integrated learning at a Saudi Arabian university. In R. Wilkinson, \& M. L. Walsh (Eds.), Integrating Content and Language in Higher Education: From Theory to Practice Selected papers from the 2013 ICLHE Conference (pp. 101-116). Oxford: Peter Lang.

Aguilar, M., \& Munoz, C. (2014). The effect of proficiency on CLIL benefits in Engineering students in Spain. International Journal of Applied Linguistics, 24(1), 1-18.

Akyel, A. S., \& Ozek, Y. (2010). A language needs analysis research at an English medium university in Turkey. Procedia-Social and Behavioural Sciences, 2(2), 969-975.

Bishop, \& Verleger. (2013). The Flipped Classroom: A survey of the research. 120th ASEE Conference \& Exposition: American Society for Engineering education. Retrieved January, 2016, from http://www.studiesuccesho.nl/wp-content/uploads/2014/04/flipped-classroom-artikel.pdf

British, C. (2015). The state of English in Higher Education in Turkey: A baseline study. Retrieved January, 2016, from http://www.britishcouncil.org.tr/sites/default/files/he_baseline_study_book_ web_-_son.pdf

Byun, K., Chu, H., Kim, M., Park, I., Kim, S., \& Jung, J. (2011). English-medium teaching in Korean higher education: Policy debates and reality. Higher Education, 62(4), 431-449.

Coşkun, A. (2013). An investigation of the effectiveness of the modular general English language teaching preparatory program at a Turkish university. South African Journal of Education, 33(3), $1-18$.

Cummins, J. (1979). Cognitive/academic language proficiency, linguistic interdependence, the optimum age question and some other matters. Working Papers on Bilingualism, 19, 121-129.

Dafouz, E., \& Guerrini, M. C. (Eds.). (2009). CLIL across Educational Levels: Experiences from primary, secondary and tertiary contexts. Madrid: Santillana Educación/Richmond Publishing.

Davison, C. (2006). Collaboration Between ESL and Content Teachers: How Do We Know When We Are Doing It Right? International Journal of Bilingual Education and Bilingualism, 9(4), 454-475.

Dearden, J. (2014). English as a Medium of Instruction: A growing global Phenomenon. Retrieved January, 2016, from http://www.education.ox.ac.uk/crdemi-oxford/emi-research/

Doiz, A., Lasagabaster, D., \& Sierra, J. (2013b). Globalisation, internationalisation, multilingualism and linguistic strains in higher education. Studies in Higher Education, 38(9), 1407-1421.

Evans, S., \& Morrison, B. (2011). The first term at university: implications for EAP. ELT Journal, 65(4), 387-397.

Graddol, D. (2006). English Next. British Council.

Inan, B., Yuksel, D., \& Gurkan, S. (2012). Expectations of Department Lecturers and/or Professors from Prep School Education and Preparatory English Language Lessons. WCES 2012. Barcelona.

Kabouha, R., \& Elyas, T. (2015). Aligning Teaching and Assessment to Course Objectives: The Case of Published by SCHOLINK INC. 
Preparatory Year English Program at King Abdulaziz University. International Journal Of Applied Linguistics And English Literature, 4(5), 72-81.

Kiliçkaya, F. (2000). Instructors' Attitudes towards English-Medium Instruction in Turkey. Humanizing Language Teaching, 8(6), 1-12.

Kirkgöz, Y. (2005). Motivation and student perceptions of studying in an English-Medium university. Journal of Language and Linguistic Studies, 1(1), 101-122.

Kirkgöz, Y. (2009). Students' and lecturers' perceptions of the effectiveness of foreign language instruction in an English-medium university in Turkey. Teaching in Higher Education, 14(1), 81-93.

Lasagabaster, D. (2011). English achievement and student motivation in CLIL and EFL settings. Innovation in Language Learning and Teaching, 5(1), 3-18.

Lehikoinen, A. (2004). Foreign-language-medium education as national strategy. In R. Wilkinson (Ed.), Integrating Content and Language. Meeting the challenge of multilingual higher education, Proceedings of the ICL Conference (pp. 41-48). Maastricht: Maastricht University Press.

Lei, J., \& Hu, G. (2014). Is English-medium instruction effective in improving Chinese undergraduate students' English competence? IRAL, 52(2), 99-126.

Llinares, A., Morton, T., \& Whittaker, R. (2012). The role of language in CLIL. Cambridge: CUP.

Lo, Y. Y. (2014). Collaboration between L2 and content subject teachers in CBI: Contrasting beliefs and attitudes. RELC Journal, 45, 181-196. http://dx.doi.org/10.1177/0033688214535054

Lo, Y. Y., \& Lo, E. S. (2014). A Meta-Analysis of the Effectiveness of English-Medium Education in Hong Kong. Review of Educational Research, 22(10), 1-28.

Lo, Y. Y., \& Macaro, E. (2012). The medium of instruction and classroom interaction: Eevidence from Hong Kong secondary schools. International Journal of Bilingual Education and Bilingualism, 15(1), 29-52.

Marshall, S., Gilmour, M., \& Lewis, D. (1991). Words that matter in science and technology: A study of Papua New Guinean students' comprehension of non-technical words used in science and technology. Research in Science and Technological Education, 9(1), 5-16.

McMullen, M. G. (2014). The Value and Attributes of an Effective Preparatory English Program: Perceptions of Saudi University Students. English Language Teaching, 7(7), 131-140.

Mercer, N. (2010). The analysis of classroom talk: Methods and methodologies (Vol. 80, pp. 1-14).

Mercer, N., \& Littleton, K. (2007). Dialogue and the development of children's thinking: A sociocultural approach. London: Routledge.

Miles, M. B., \& Huberman, A. M. (1994). Qualitative Data Analysis: An Expanded Sourcebook. Newbury Park, CA: Sage.

Murray, N. (2013). Widening participation and English language proficiency: A convergence with implications for assessment practices in higher education. Studies in Higher Education, 38(2), 299-311. 
O'Dowd, R. (2015) The training and accreditation of teachers for English Medium Instruction: A survey of European universities. Retrieved July, 2015, from http://sgroup.be/sites/default/files/EMI\%20Survey_Report_ODowd.pdf

Othman, J., \& Saat, R. M. (2009). Challenges of Using English as a Medium of Instruction: Pre-service Science Teachers' Perspective. The Asia-Pacific Education Researcher, 18(2), 307-316.

Pavon, V. V., Avila, L. J., Gallego, S. A., \& Espejo, M. R. (2015). Strategic and organisational considerations in planning content and language integrated learning: A study on the coordination between content and language teachers. International Journal of Bilingual Education and Bilingualism, 18(4), 409-425.

Probyn, M. (2001). Teachers' reflections on learning and teaching through the medium of English as an additional language in South Africa. International Journal of Bilingual Education and Bilingualism, 4(4), 249-266.

Rauhvargers, A. (2013). Global Universities Rankings and Their Impact: Report ii. Brussels: European University Association. Retrieved July 14, 2015, from http://www.eua.be/Libraries/Publications_homepage_list/EUA_Global_University_Rankings_and _Their_Impact_-_Report_II.sflb.ashx

Teddlie, C., \& Tashakkori, A. (2008). Foundations of Mixed Methods Research: Integrating Quantitative And Qualitative Approaches In The Social And Behavioral Sciences. London: Sage.

Tedick, D. J., \& Cammarata, L. (2012). Content and Language Integration in K-12 Contexts: Student Outcomes, Teacher Practices, and Stakeholder Perspectives. Foreign Language Annals, 45, 28-53.

Wingate, U. (2015). Academic Literacy and student diversity: The case for inclusive practice. Bristol: Multilingual Matters.

Yassin, S. M., Tek, O. E., Alimon, H., Baharom, S., \& Ying, L. Y. (2010). Teaching Science Through English: Engaging Pupils Cognitively. International CLIL Research Journal, 1(3), 46-59.

\section{Appendix A}

\section{Collaborative Session 1}

EMI Teacher name: PYP Teacher name:

Academic Subject: Date:

Lecture/Session Title:

\section{Collaborative (PYP/EMI) planning:}

Briefly discuss the learning objectives for this session. Do you wish to include any language learning objectives as well as content objectives?

Pre-lecture reading text

\section{Collaborative (PYP/EMI) planning:}

Identify potential challenges in this text for your students. 
Lexical Level

- What general academic vocabulary is being used?

- $\quad$ Are there any ambiguities in this academic vocabulary?

- Will they be able to distinguish between academic vocabulary and subject-specific technical terms?

- Identify the technical terms: have the students come across them before?

- How are the technical terms explained in the text: through definition, paraphrase, exemplification?

- If students look up general academic or technical terms in a dictionary, will their meaning be clear?

Sentence Level

- Are there any structural difficulties presented by the text, for example frequent use of subordination, use of the passive, etc.?

Are there any other difficulties presented by the text?

[insert pre-lecture reading text]

Lecture notes and/or PowerPoint slides

Collaborative (PYP/EMI) planning:

Discuss what you are trying to achieve with the slides you are going to use in your lecture/session.

- Is it to add to the text(s) the students have read?

- Is it to mediate the text(s) they have read?

- Is it to give new information not directly related to what they have read before?

Consider the notes or slides you have chosen to show the students.

- $\quad$ Are you using the same academic vocabulary as in any associated texts or topics?

- Are you using different vocabulary to explain the same thing?

- What difficulties might your students experience in understanding or following your slides?

What are you highlighting in your notes or slides? What is the purpose of this highlighting?

[insert lecture notes and/or PowerPoint slides]

Your own language use

Collaborative (PYP/EMI) planning:

- What oral language are you planning to use in delivering this class or lecture?

Discuss how what you say to the students relates to the lecture notes or slides. 


\section{Appendix B}

\section{Collaborative Session 2}

Reflect on how this lecture/session went.

\section{Notes}

Note 1. Ministry of Education (Turkey) (2016) retrieved January 2016 at http://www.meb.gov.tr

Note 2. All named participants are pseudonyms and we have also withheld the name of the institution in order to guarantee anonymity. 